Dr. Heien BeTrs, in referring to the question of a woman nursing when pregnant, thought that few women were able to nurse a baby and carry a foetus at the same time without injury either to themselves or to those in their charge. In most cases it seemed wise to withdraw a part of the burden by directing that the child be weaned.

The President, in commenting upon the specimen presented by Dr. Norris, said it was one not only of exceptional interest, but represented a whole series of placental changes which, until recently, had been but little understood. 'The late distinguished Professor G. B. Lircolani, of Bologna, rendered a service to the profession of incalculable value in his studies of placental development, and his demonstrations, after long and patient research in the large field of comparative as well as human anatomy, are of the first importance to science. He shows conclusively that fotal alimentation in all mammals is carried on by a single, universal law of physiological modality, that the fotal villus is simply a means of absorption of nutritive material, which is, in all cases, furnished by a glandlular, secretive organ of maternal development. The expression of this anatomical type is of the widest variety, and in woman, in the fully developed placenta, reaches a complexity of form confusing in the highest degree. The chorial villi, which during the earlier months of pregnancy are developed over the entire surface of the chorion, are composed of two parts, internal and external. The first, which was called by Robin chorial tissue, and by Virchow mucous or myxoma, is in direct contact with the chorion; the latter, which consists of an epithelial envelope, entirely surrounds it. 'The villi, at the placental site, increase normally in num. ber and volume. lisewhere, they are arrested in their growth and disappear by atrophy and fatty degeneration. The decidua is, at first, a single bed of cells of new formation, and afterward proliferates to a remarkable degree at the placental site-the decidua serotma. The epithelial covering of the placental villi is perceived same time after they have been enveloped by the cells of the serotina. but disappear at an early period. Not seldom, in case of so-called mole pregnancy, the choroid villi, which should atrophy, increase in volume. Under these conditions the external epithelium does not atrophy, but proliferates, and has been mistaken for the intemal surface of the eputhelium furnished to the placental villi from the modified cells of the serotina. At the later stages of pregnancy, the examination of any remaining choroid villi shows them still covered with an epithelial layer, while the placental villi have lost this envelope and are formed only of the funclamental myxomatous tissue which encloses the fotal vessels, and thus the external parenchyma of the villi is in contact with the internal epithelium of the sur. rounding glandular organs.

Pathological conditions, such as are represented in this specimen, where the fotus has been for some time dead and the placenta has remained undisturbed in its attachments to the uterus, give conlimatory evidence of the truth of the demonstrations of $\mathrm{kr}$ colani. I have frequently observed, microscopically, the close contact of the choriol villi with the epithelial covering of the maternal vessels when the placenta has been undisturbed in connection with the uterus for a considerable period after the death of the fortus. The choriol villi have become shrunken, and are easily separated from the decidual sheath, the cells of which have undergone active proliferation. In one instance this was observed to have taken place and continued in a stage of active development, in a portion of a placenta removed three months after the expulsion of the foetus.

Dr. Marcy was glad to have the attention of the Society called to this class of specimens. They are of interest from the practical side of observation and often involve danger to two lives. The pathological committee of the Society will gladly investigate and report upon any specimens which may be forwarded to them.

\section{MEDICAL SOCIETY OF THE DISTRICT OF COLUMBIA.}

Stated Meetinir, Felrnary 17, 1886.

Vice-Prlisident, John B. Hamition, M.D., in THe Cuatk.

T. E. McArdie, M.D., Secretary.

DR. C. V. BOARMan read a paper on

JAUNDICL FOLLOWING CONCUSSION OF THE BRAIN.

On December 30,1885 , I was called to see J. B., age 30 ; married; a laborer at the Monument; who, whilst assisting at some mechanical work, lost his balance and fell a distance of thirty feet, striking upon his head, tearing the scaly) from and exposing for several inches squiare the vertex of his skull, he also bruised and lacerated his forehead in several places. His body and limbs were also bruised. I found him at his home (to which he was brought in a carriage), in a sitting posture, apparently dazed; would answer questions in monosyllables after their repetition in a loud voice, was spitting blood and his nose bleeding.

I washed the semi-detached scalp in carbolized water and reapplied it in its proper place, holding it there by means of a stitch and adluesive plaster, ordered him to be put to bed at once and Jotions applied to his face and other bruised parts. About six hours after a messenger came to my office to ask for something to relieve Mr. B.'s sick stomach, and also notified me that he had vomited about a pint of coagulated blood, and that there was still considerable retching and nausea. I at first thought that the above might be caused by compression, but as I gave the injury a very thorough examination at the lime I saw it and discovered notling of the kind, 1 concludec! that it was due partly to the concussion, and also the blood which had run down the cesophagus from the posterior nares, as there was considerable epjstaxis. I ordered ice, lime-water and milk, also some ingluvin, and after a few hours bromide potass. in solution, as there was considerable excitement, groaning and jactitation.

December 3r. Mr. 13. was quietly resting upon 
his back in bed upon my arrival, perfectly conscious, 'became jaundiced within three hours after an unsucno headache or sick stomach, but still spitting up cessful attempt to catheterize the bladder; the skin blood. He stated that after vomiting copiously the remained yellow for four days and the urine contained night before, he felt much better, became perfectly bile-pigment one day longer. Its sudden onset and conscious and passed a good night. The vomiting rapid disappearance are in favor of its being of neuwas no doubt as much dependent upon the blood rotic origin. Another case of interest having a rewhich had run down his oesophagus as upon the concussion of the brain. I examined his wounds and found them doing well; very little suppuration, the scalp-wound inclined to unite. The entire head, face, and even the neck was very much swollen, looked like it was puffed up with air, but no redness or tenderness; in fact, no positive symptom of erysipelas. His sclerotics were congested and effused, the surrounding parts black from bruises. He complained very much of soreness about his knees and shoulders, which were no doubt struck by projecting beams during his descent.

January I. Upon visiting Mr. B., to my astonishment I found him intensely jaundiced, his sclerotics stained, urine loaded with bile-pigment, and all other symptoms indicative of icterts. I never saw a person more changed in appearance; being in health a very tall, thin man, his features sharp and cheek-bones prominent, his present condition was such that he was hardly recognizable, as his face was terribly swollen and as yellow as saffron, the bruises and lacerations of course adding to the above abnormal appearance. I removed the stitch from the scalp-wound, which had united by first intention. His other injuries, notwithstanding his jaundiced condition, were doing well; he was still spitting up some blood, but not enough to cause any alarm. I ordered a mercurial purgative, after the action of which I placed him upon nit. muriatic acid dilut., at the same time, of course, regulating his diet, forbidding the fats, oils, etc. 'The purgative acted well, bringing away a large amount of black grumous matter, no cloubt partially digested blood and feces. He felt considerably relieved after his bowels acted, and left the bed.

January 3. His condition was very much improved, the jaundice rapidly disappearing, and the swollen and bruised parts resuming their normal condition. I did not see Mr. B. again until January 5 , which was my last visit, as the jaundice had disappeared, and his various injuries were doing well, he was up and anxious to resume his work.

I look upon the above case as tare, as in the majority of cases the physician is able to trace the disease to obstructions either existing in the intestinal canal or common duct, whereas in the above the solution of the difficulty is hard, unless we accept the theory advanced by Murchison, that concussion of the brain produces jaundice by interfering with or deranging the normal metamorphosis of bile by nervous intluences. Virchow mentions a form as hematogenic, that is, formed in the blood or taking its origin there. Ponfick assigns as a cause violent mental conditions, as for instance anger, etc. Murchison speaks of the case of a soldier who became jaundiced because he was restrained from wreaking his vengeance on a comrade who had angered him.

M. Rendu records the case of a woman aged 25 years, convalescent from puerperal peritonitis, who mote origin or cause is mentioned by Dr. Boucher in the London Lancet, July, 1884 : A child aged 2 years sat down in a pail of hot water in which there was dissolved a quantity of soda. The scalding was confined to the nates, on which there were two large blisters, they were treated by the usual methods. On the tenth day after, there was abdominal tenderness with pain, high temperature and diarrhoea, the urine contained bile-pigment, sclerotics and skin stained; in a word, a well-marked case of jaundice. It lasted three or four days, and then subsided. This case was no doubt owing to inflammation extending to the mucous membrane of the common duct, causing an obstruction to the outward flow of bile, which in turn was followed by jaundice.

It is frequently very difficult to assign a cause for jaundice, as its appearance at times is so eccentric; for instance, the jaundice of pyemia, and those forms of the disease resulting from the barcotism of chloroform, and other forms of intoxication. It also occasionally complicates pneumonitis. I think the case just reported by me was due to neurotic influences, as its appearance and disappearance were so sudden. Besides, I examined his urine by the usual methods, and failed to find the biliary acid, which, according to Dr. (i. Harley, is proof that no obstruction existed, as he adopted the theory wlich had been advanced, "that the liver manufactures the bile acids, while it merely excretes the bile-pigment."

1)k. A. Y. P'. (GAKNET' said that jaundice is often due to trammatism. Although he liad no personal experience with the disease resulting from such a cause, yet the journals frepuently contain reports of similar cases. Nervous influences operate in a great variety of ways. Some women suffer from jaundice during the period of the menses. Some reflex irritation traceable to the uterus or ovaries produces an icteroid condition which disappears with the cessation of the menstrual llow. We know that the presence of the infant seeking nourishment will produce an increase of maternal milk. The appearance of food causes a secretion of saliva. Not only quantitative but qualitative effects follow mental emotions. Passion has a deleterious influence on normal secretions. Fear had turned turned hair gray almost instantaneously. Dr. (jarnett also spoke of jaundice following the bite of serpents.

DR. J. FOKD 'Thompson had no experience. with jaundice as a sequence of concussion of the brain. He had seen icterus follow injuries about the skull, and he had seen the yellow discoloration of pyamia and septicamia; but he did not consider this condition pathological jaundice. It is different from a jaundice caused by an impediment to the excretory ducts or by a catarrhal condition. In such cases there would be an absorption of bile after its manufacture by the liver. When we get to explaining things by nervous shock we do not get much satisfaction. 
Dr. Boarman contended that jaundice may be a symptom of nervous derangement. In this case he found bile pigments and biliary salts in the urine. It looks, of course, as if an obstruction existed. The patient had headache and nausea, both symptomatic of jaundice. 'There was at no time even a suspicion of pyamia or septiciemia. The pulse was slow; but that condition is common in jaundice. Murchison says that nervous infuences can and do produce jaundice.

Dr. Garnitry said that the metabolic activity of the hepatic cells in the production of bile is in direct proportion to the plus or minus degree of blood pressure in the liver. Any agent or cause disturbing the normal physiological equilibrium of blood pressure in that organ directly affects the secretion of bile. It has been shown that a section of the splanclunic nerves causes immediate dilatation of the hepatic veins, followed by a diminution of arterial blood pressure and increased flow of blood into the portal veins. It is easy then to conceive how readily causes disturbing the normal functions of the nerves supplying the liver, and especially the great sympathetic, whose filaments supply the vaso-motors of the hepatic arteries, may affect the secretion and diffusion of bile.

DR. BOARMAN said that Buld concurred in Boerhaave's and Morgagni's idea, with the exception that no bile acid was found in the blood of the portal vein. Prof. Freidrich states that bile acid taken from the liver by blood of hepatic vein, and also absorbed from bowel, etc., undergoes in the blood a change. Bile acids converted by oxidation, a normal metamorphosis, into taurin, are found in healthy lungs, and taurin and pigment are voided in the urine.

1)R. A. II. A. KING inquired whether the body was examined all over? If the discoloration was general? If there was bile in the stools? He thought the discoloration resulted probably from bruising. He said that it was important to determine whether a yellow coloration of the surfaces is really due to the principle of the bile, and mentioned the true jaundice of the new-born, and its spurious counterpart.

D. R. BOARMAN had examined the body generally but not the abdomen. The urine, he repeated, contained the biliary salts, the faces were scanty, and the color of dog's dung.

DR. H. D. likv asked on what symptoms the diagnosis of concussion of the brain were based?

DR. BOARMan repeated the symptoms mentioned in his paper.

Dr. FRy thought it was important to have examined the abdomen for possible injury.

DR. BOARMan said that he had mentioned such a possibility in his paper.

J). J. B. Hamniron said it seemed the literature had been hastily treated. 'The antopsies made by Valsalva had not shown any intimate relation between concussion of the brain and hepatic abscess. Chelins says liver abscess and jaundice are common as late symptoms. l3allugall, Guthrie and Gross also mention it. Dr. Hamilton thinks the only explanation of its production has been that it is due to an irritation of the floor of the fourth ventricle and by the pneumogastric nucleus. He agrees with Dr. Boarman that it is a rare but long-recognized condition. Duret's examination showed extravasation in the fourth ventricle in a great many cases of concussion.

DR. KING could not see the connection between a jaundice resulting from old liver disease, as abscess, and the acute symptoms described in the paper.

1)k. HamirTon spoke in general terms, and in reply to Dr. Boarman said be thought that nervous jaundice, like diabetes mellitus, might be produced by compression in the fourth ventricle due to extravasation.

\section{DOMESTIC CORRESPONDENCE}

\section{LETTER FROM NEW YORK.}

(WKOM OUR OWN COKKUSHONDICNT.)

The Belliane Commencement-The Funcral of Dr. Flint-7he Death of Dr. S. O. Vanderpoel-The University Commencoment.

The commencement of the Bellevue School, which came off on the evening of March 15, was the saddest that this, or probably any other medical college, ever had. The week before had been buried the accomplished and popular young Demonstrator of Anatomy, Gaspar Griswold, and at the time of its occurrence the mortal remains of the immortal teacher and writer, Austin Flint, lay in their coffin awaiting the funeral scrvices of the morrow. Under the circumstances the exercises were naturally of a memorial character, instead of the festal nature usual on such occasions. 'They were entirely private, being held in the lecture room of the Carnegie Laboratory, connected with the college, instead of some such place of amusement as the Metropolitan Opera House or the Academy of Music, and the building was elaborately and tastefully draped in the emblems of mourning. It was indeed a most affecting event. In his remarks to the graduating class, which numbered 140 , the President, 1)r. Isaac li. 'I'aylor, spoke in feeling terms of the great bereavement of the college and the profession, and the eminent physiologist, Dr. John C. Dalton, now President of the College of Physicians and Surgeons, paid a most touching and eloquent tribute to the dead professor.

'lhe funeral services, which were held linesday, March 16, at Christ Church, of which I)r. Fline was a member, were of the greatest possible simplicity, and there were no pall-bearers. 'The church was completely filled with the Faculties and students of Bellevue and the other medical schools, representatives of the New York County Medical-Association, the County Society and the Academy of Medicine, and citizens generally; and among those present were many distinguished men of other callings, as well as a number of well-known physicians from other cities. At the head of the coffin, beside which stood, during the whole service, the faithful negro servant of Dr. Flint, was a large and beautiful broken column, rising from a floral base, which was the offering of the 